\title{
KONSELING ART DENGAN MEDIA GAMBAR UNTUK MENINGKATKAN SELF DISCLOSURE MAHASISWA
}

\author{
KARYANTI \\ Dosen Program Studi Bimbingan dan Konseling Fakultas Keguruan dan IImu Pendidikan \\ Universitas Muhammadiyah Palangkaraya \\ Email : karyanti982@gmail.com
}

\begin{abstract}
A university students need to express themselves in making friend relationship with other university students. Self-disclosure is an act to tell about the private self condition to the other university students voluntarily. University students' self-disclosure can reduce the anxiety felt by themselves when they are making friend relationship with other university students. The anxiety experienced by the university students in making friend relationship can make them to become difficult to express their opinions, feelings, and they will not share any information with other university students. The university students who are difficult to express themselves will experience uncomfortable conditions and tends to be avoided by the other university students. The focus of the university students' self-disclosure to other university students is an intervention or special counseling strategies offered. By hoping that when the counselling strategy can be implemented, it can overcome the problems of less harmonious friendship between the university students. Counselling strategy that offered to the university students' self-disclosure is a self disclosure training by using art counseling with pictures media.
\end{abstract}

Keywords: self-disclosure, art counseling, pictures

\begin{abstract}
ABSTRAK
Mahasiswa dalam menjalin hubungan persahabatan dengan mahasiswa lain perlu mengungkapkan diri. Pengungkapan diri (self-disclosure) adalah tindakan menceritakan keadaan diri yang bersifat pribadi pada mahasiswa lain secara sukarela. Pengungkapan diri mahasiswa dapat mengurangi kecemasan yang dirasakan oleh diri sendiri ketika menjalin hubungan persahabatan dengan mahasiswa lain. Kecemasan yang dialami oleh mahasiswa dalam menjalin hubungan persahabatan mengakibatkan dirinya sulit untukmenyampaikan pendapat, mengungkapkan perasaan, dan tidak akanberbagi informasi kepada mahasiswa lain. Mahasiswa yang sulit mengungkapkan diri akan mengalami kondisi yang tidak nyaman dan cenderung dijauhi oleh mahasiswa lain. Fokus pengungkapan diri mahasiswa kepada mahasiswa lain adalah intervensi atau strategi konseling khusus yang ditawarkan. Dengan harapan bahwa ketika strategi konseling dilaksanakan dapat mengatasi masalah hubungan persahabatan yang kurang harmonis antar mahasiswa.Strategi konseling yang ditawarkan untuk pengungkapan diri mahasiswa adalah pelatihan self disclosure menggunakan konseling art dengan media gambar.
\end{abstract}

Kata kunci : self disclosure, konseling art, gambar

\section{PENDAHULUAN}

Mahasiswa dalam pergaulan di lingkungan kampus cenderung memiliki penilaian negatif terhadap diri sendiri dan mengindari mahasiswa lain. Indikasi dari mahasiswa yang menilai negatif terhadap diri sendiri dan menghindari mahasiswa lain, cenderung akan mengalami hubungan persahabatan yang kurang harmonis dengan mahasiswa lain dan ragu-ragu mendekati mahasiswa lain karena takut ditolak. Mahasiswa yang cenderung memiliki hubungan persahabatan yang kurang harmonis dengan mahasiswa lain di 
lingkungan kampus lebih rentan terhadap pengucilan sosial. Mahasiswa untuk menghindari hubungan yang kurang harmonis dengan siswa lain memerlukan sebuah keterampilan sosial.

Mahasiswa memerlukan keterampilan sosial agar berhasil menjalin hubungan persahabatan yang harmonis dan terhindar dari pengucilan oleh mahasiswa lain di lingkungan kampus. Salah satu aspek yang penting dalam keterampilan sosial adalah self disclosure.Self disclosure (pengungkapan diri) adalah membangun informasi dua dimensi, disusun oleh kedalaman (informasi yang diungkapkan) dan luasnya informasi yang diberikan (berbagai tema yang dibahas). Informasi yang lebih dalam dan lebih luas dalam pengungkapan diri mengarah ke hubungan interpersonal yang baik (Altman dan Taylor,1973; Harper \& Harper, 2006; dan Tolsdtedt dan Stokes, 1983; dalam Matulaitiene \& Paluckaite, 2013:458). Jourard (dalam Hill, dkk, 2007:52) menyatakan bahwa self disclosure adalah cara dimana kita semakin dapat berbagi informasi tentang diri Anda sendiri dan mengeksplorasi bagaimana mahasiswa lain melihat Anda.

Self disclosure cenderung membuat mahasiswa lain untuk memahami keadaan diri Anda. Self disclosure adalah salah satu variabel penting dalam menjalin hubungan persahabatan antar mahasiswa di lingkungan kampus. Karya awal Jourard (dalam Leung, 2002:243) percaya bahwa variabel penting untuk dipertimbangkan ketika mempelajari self disclosure dalam hubungan persahabatan itu adalah jumlah informasi yang disampaikan. Sejak saat itu para peneliti menyebutkan terdapat multi-dimensi self disclosure.
Multidimensi self disclosure dalam menjalin hubungan persahabatan antar mahasiswa dapat membuat mahasiswa saling menerima kelemahan dan kelebihan dari mahasiswa lain dan cenderung saling membantu antar mahasiswa. Namun, terdapat mahasiswa yang kurang dalam self disclosure sehingga mahasiswa tersebut cenderung dikucilkan oleh teman-teman di kelas. Mahasiswa yang dikucilkan di kelas akan sulit mencapai prestasi akademik, dikarenakan tidak ada teman yang mau mengerjakan tugas kuliah atau sekelompok dengan mahasiswa tersebut.

Melihat kondisi mahasiswa seperti itu fungsi dari pendidikan untuk mempersiapkan generasi muda yang bertanggung jawab terhadap tugasnya di masa yang akan datang seolah sulit untuk diwujudkan. Perlu diupayakan sebuah bantuan untuk melatih mahasiswa sebuah keterampilan baru, agar mahasiswa dapat menjalin hubungan persahabatan yang harmonis dengan mahasiswa lain di kelas dan lingkungan kampus. Keterampilan baru agar potensi mahasiswa berkembang ke arah yang optimal baik sebagai pribadi maupun sebagai mahasiswa yang sedang berada dalam proses perkembangan. Keterlibatan orang dewasa seperti seperti dosen dan konselor dalam lingkup kampus memegang peran penting memberikan bantuan dalam layanan bimbingan dan konseling yang efektif dan efisien bagi mahasiwa yang kurang mampu melakukan self disclosure. Bentuk-bentuk layanan yang perlu diberikan kepada mahasiwa yang kurang mampu melakukan self disclosure salah satunya adalah layanan konseling kelompok dengan teknik konseling art. 


\section{Self Disclosure}

Pengungkapan diri (self disclosure) adalah campuran dari dua bagian. Pertama, ada wujud menarik 'diri' dan apa sebenarnya. Kedua, ada proses 'pengungkapan' dimana individu membuka beberapa aspek diri kepada mahasiswa lain. Altman \& Taylor (dalam Sprecher \& Hendrick 2004: 858) menyatakan bahwa pengungkapan diri (self disclosure) adalah proses memberitahu mahasiswa lain tentang perasaan, sikap, dan pengalaman. Ini telah digambarkan sebagai kemajuan dalam mode yang relatif sistematis, dimulai dengan luasnya pengungkapan dan bergerak menuju pengungkapan yang lebih mendalam. Jourard (dalam Allen \& Court, 2009) menyatakan bahwa self disclosure adalah tindakan yang membuat diri Anda nyata, menunjukkan diri Anda sehingga orang lain dapat melihat Anda.

Woodward (dalam Hargie, 2011:239) menyatakan bahwa self disclosure adalah proses antara bersama individu, dimana diri diberbentuk, bernegosiasi dan diubah. Dengan cara ini, identitas dibentuk oleh kombinasi dari bagaimana Anda melihat diri Anda sendiri dan oleh bagaimana mahasiswa lain melihat Anda.

Jourard (dalam Leung, 2002: 243) menyatakan bahwa terdapat multi-dimensi self disclosure. Dimensi self disclosure yaitu: (a) kedalaman atau keintiman; (b) kejujuran atau akurasi;(c) jumlah yang berlangsung; (d) valensi (derajat); dan(e) intensional dari pengungkapan diri. Wheeless dan Grotz (dalam Leung, 2002: 243) melaporkan hubungan positif antara jumlah, kedalaman, dan kejujuran dari keterbukaan diri dengan kepercayaan dalam hubungan. Orang sehat cenderung mengungkapkan diri lebih positif daripada informasi negatif dan untuk membuat lebih banyak keterbukaan diri untuk mereka.

Derlega dkk, (dalam Sprecher \& Hendrick, 2004:860) menyatakan bahwa Salah satu variabel perbedaan individu sering diperiksa di sebelum penelitian self disclosure adalah gender. Perempuan biasanya berpikir untuk mengungkapkan lebih dari laki-laki, dan temanteman perempuan memang tampak lebih mengungkapkan diri satu sama lain daripada teman-teman laki-laki lakukan.

Menurut penelitian self disclosure memiliki efek positif pada kesehatan fisik (Locke \& Colligan, 1986; Pennebaker, 1989; dalam Beiman; 2013;63), yang berfungsi sebagai sumber katarsis dan bantuan untuk menyampaikan informasi diri (Stiles, 1987, 1995; dalam Ziv-Beiman; 2013;63). Mahasiswa memerlukan keterampilan dalam menyampaikan informasi mengenai diri sendiri kepada mahasiswa lain. Keterampilan baru self disclosure mahasiswa salah satunya teknik konseling art dengan media gambar.

\section{Konseling Art}

Berbicara bahasa sehari-hari, kerangka awal ini memandang seni sebagai bentuk materi yang meningkatkan kehidupan seseorang dengan kenikmatan telinga, pikiran, dan mata. Zolberg (dalam Paul, 2005:2) menyatakan bahwa "seni," mengacu pada seni visual dan pendengaran, misalnya, lukisan, patung, dan musik. Namun seni juga dapat dikonseptualisasikan termasuk sastra, teater dan media yang dihasilkan bentuk seni, misalnya, iklan, film, komedi situasi televisi, dll (Zolberg 1990:4). 
Sejak tahun 1940-an, dua goal dan fokus seni dalam konseling telah berubah dari sikap psikoanalitik. Pertama, yang mendukung ego, mendorong pengembangan identitas, dan kedua, mempromosikan kematangan. Konselor dapat menggunakan seni sebagai intervensi konseling. Junge \& Asawa (dalam Malchiodi, 2003: 6) menyatakan bahwa pengembangan profesi konseling art (art therapy) dapat dilihat sebagai aplikasi resmi tradisi manusia dahulu dipengaruhi tren intelektual dan sosial abad ke-20.

Nucho dkk (2003: 12) menyatakan bahwa konseling art adalah proses budidaya, mengklarifikasi, dan visual mengekspresikan citra yang muncul secara spontan dalam menanggapi berbagai pengalaman dalam hidup. Gambar yang simbolisasi atau kristalisasi dari pengalaman hidup. Pengalaman dalam hidup yang diringkas menjadi gambar baik secara spontan dan sengaja. Bahasa itu sendiri mungkin dipandang sebagai suatu sistem beku gambar. Tapi apa tujuan tingkat simbolisasi ini? Mengapa manusia dilengkapi dengan kemampuan untuk menghasilkan gambar, baik secara spontan dalam mimpi dan sengaja dalam seni, dan tak terelakkan dalam pidato dalam bentuk metafora?

Konseling art adalah bentuk aktif dari konseling. Konseli terlibat dalam manipulasi bahan fisik dan berpikir tentang masalah Anda dengan cara baru. Mewakili konflik atau perasaan dalam gambar pensil, kolase, atau patung tanah liat memungkinkan konseli secara harfiah untuk melihat masalah konseli dari semua sisi.

Malchiodi (2003: 16) menyatakan bahwa konseling art secara historis menolak hubungan dengan ilmu pengetahuan dan sangat disukai karena lebih berbasis seni sikap dalam filsafat dan praktiknya. Namun, temuan ilmiah baru-baru ini tentang bagaimana gambar mempengaruhi emosi, pikiran, dan kesejahteraan dan bagaimana otak dan tubuh bereaksi terhadap pengalaman menggambar, melukis, atau kegiatan seni lainnya mengklarifikasi mengapa konseling art mungkin efektif dengan berbagai populasi. Camic (dalam Malchiodi, 2003:17) melaksanakan studi menggunakan seni visual dan bentuk seni lainnya bersama dengan teknik kognitif-perilaku, meditasi, dan pencitraan mental untuk mengurangi rasa sakit kronis pada orang dewasa.

Case dan Dalley (dalam Liebmann, 2004:6) menyatakan bahwa konseling art melibatkan penggunaan media seni yang berbeda di mana konseli dapat mengekspresikan dan bekerja melalui isu-isu dan keprihatinan yang telah membawa konseli pada konseling. Konselor dan konseli dalam hubungan kemitraan berusaha untuk memahami proses seni dan sesi produk. Malchiodi et al., (dalam Malchiodi, 2003: 22) menyatakan bahwa kegiatan seni sederhana seperti menggambar sangat menyenangkan, tampak efektif karena kapasitas sensorik membuat gambar untuk lebih dalam mengingat kenangan sebenarnya dan sebuah rincian positif.

Malchiodi (2003:245) menyatakan bahwa sketsa, gambar, dan lukisan dapat digunakan dalam proses konseling art. Pemilihan intervensi artistik yang digunakan untuk konseling harus didasarkan pada isu-isu konseli dan model ekspresi diri yang konseli sukai. Berbagai jenis kegiatan yang melibatkan sketsa, menggambar, dan melukis hanya dibatasi oleh konselor dan imajinasi konseli. Salah satu teknik konseling yang digunakan dalam konseling art adalah menggambar. 
Benson (dalam Malchiodi, 2003:18) menyatakan bahwa gambar dapat membuat sensasi kesenangan, ketakutan, kecemasan, atau rasa tenang, dan ada bukti bahwa mereka dapat mengubah suasana hati dan bahkan menginduksi rasa kesejahteraan (keamanan, keselamatan, ketenteraman).Terapis seni vija Lusebrink (dalam Malchiodi, 2003:18) mengamati bahwa gambar yang "menjembatani antara tubuh dan pikiran, atau antara tingkat kesadaran untuk pengolahan informasi dan perubahan fisiologis dalam tubuh.Memandu pencitraan, proses pengalaman di mana seorang diarahkan melalui relaksasi diikuti dengan saran untuk bayangkan gambar tertentu, telah digunakan untuk mengurangi gejala, mengubah suasana hati, dan melepaskan kapasitas penyembuhan tubuh.

Malchiodi (dalam Chibbaro \& Camacho, 2011:41) menyatakan bahwa sketsa, menggambar, dan melukis dapat digunakan sebagai alat konselor karena memungkinkan mahasiswa untuk secara express visual dan melepaskan emosi mereka serta meningkatkan keseluruhan kesehatan dan kesejahteraan. Mahasiswa yang mengalami kesulitan berbicara tentang kehidupan memalukan atau mengekspresikan peristiwa yang mengakibatkan trauma. Seperti peristiwa kekerasan keluarga dan pelecehan yang dialami oleh mahasiswa.

Gladding (dalam Malchiodi, 2003:243) menyatakan bahwa konseling art pada orang dewasa tidak memadai karena orang dewasa merasa kemampuan mereka kurang atau malu untuk lebih mengekspresikan diri secara artistik. Namun demikian, ada banyak manfaat dicatat ketika menggunakan seni sebagai bagian dari konseling dengan konseli. Meskipun manfaat ini telah dijelaskan, berikut keuntungan tertentu dari konseling art dengan orang dewasa: 1) alam bawah sadar dan membantu individu mengungkapkan konflik terselubung, membawa kedalam pikiran kesadaran dan perasaan yang sebelumnya tersembunyi (Liebmann,1990); 2) bertindak sebagai metafora untuk konflik, emosi, dan situasi yang dialami oleh konseli (Ulak \& Cummings, 1997).

\section{Proses Konseling Art Dengan Teknik Menggambar}

Konselor bekerja dengan konseli dewasa dapat menggunakan berbagai bentuk seni visual untuk memfasilitasi tahapan yang berbeda dari proses konseling. Penggunaan media ini akan menjadi lebih rileks dan kreatif (Makin 1994; Nadeau,1984; dalam Malchiodi, 2003:245).

Proses menciptakan gambar untuk mewakili pengalaman batin terinspirasi oleh Jung (dalam Malchiodi, 2003:248), yang menarik, dicat, dan dipahat representasi dari mimpi dan pengalaman fantasi. Berdasarkan nilai psikologis ia secara pribadi ditemukan dari menjelajahi gambar, Jung kemudian mendorong pasien untuk membuat gambar visual mereka pengalaman batin sendiri (Edwards, 1987; dalam Malchiodi, 2003:248). Penggunaan gambar dalam konseling tidak terbatas pada konselor yang terlatih dalam psikologi Jung. Konselor berbagai teori orientasi dapat menyediakan konseli dengan kesempatan untuk membuat gambar untuk memfasilitasi pelepasan pengalaman emosional atau mungkin menekan trauma.

France dan Allen (dalam Malchiodi, 2003:248) menggunakan pendekatan Gestalt untuk membuat gambar dengan konseli remaja pengganggu untuk membantu meningkatkan 
kesadaran tentang perasaan dan mengintegrasikan kembali yang bertentangan dalam diri agar perasaan lebih sehat. Pendekatan ini terdiri dari empat langkah, yaitu: pemanasan, tindakan, berbagi, dan berdialog. Pada tahap pemanasan, konseli berbicara tentang kekhawatiran tertentu atau dilema dan pikiran konseli dan perasaan tentang keprihatinan konseli. Dalam pelaksanaan, konselidiminta untuk membuat gambar yang mewakili kekhawatiran. Setelah gambar dibuat, konseli berbagi apa yang telah konseli simpulkan dengan konselor. Langkah ini diikuti dengan berdialog, konselor mengajukan pertanyaan spesifik untuk membantu konseli mengeksplorasi kemungkinan terkait dengan gambar. Konselor mungkin mengajukan pertanyaan seperti berikut: "? Perasaan apa yang kamu gambarkan" "Apa sekarang kamu sadar? "'Apa energi gambar? "' Apa yang hilang? "Atau, konselor dapat mendorong konseli untuk memilih objek tertentu dalam gambar benda-benda dan role-play. Kadang-kadang, itu bermanfaat bagi konselor untuk memainkan peran salah satu gambar (Coan, 2000). Pengambilan gambar pengalaman alam ini membantu menempatkan dilema dalam perspektif, memberikan kesempatan bagi wawasan, dan mengungkapkan kemungkinan tambahan dan pilihan untuk hidup.

Gambar yang dibuat konselor sering mengambil bentuk penokohan. Sebagai contoh, sketsa singkat dari apa yang "menekankan" sepertinya dapat menghasilkan dialog tentang suatu gaya hidup konseli. Jika pembicaraan konseli tentang perasaan "dibebani" dengan beban, yang konselor dapat mencirikan beban dalam sebuah gambar, sehingga mendorong konseli untuk mengeksplorasi masalah lebih lanjut. Hal ini penting untuk membuat gambar secara mendadak, individual,dan rahasia (Edens et al., 1996; dalam Malchiodi, 2003:249). Implementasi lain darigambar yang dibuat konselor, konselor memiliki potensi untuk masuk sepenuhnya ke dalam dunia konseli dengan cara yang unik.

Hammond dan Gantt (Malchiodi, 2003:249) menyatakan bahwa "setiap konselor terlatih harus dapat berbicara dengan konseli tentang sebuah karya seni dibawa ke sesi. Selanjutnya, konselor harus mampu mendorong konseli untuk menggambar atau melukis gambar ketika berbicara menja di sulit, klarifikasi diperlukan, atau konseli diblokir dalam menggambarkan sesuatu. Namun, penting untuk menghindari menantang etika batas dengan menafsirkan seni konseli ke konseli atau membuat generalisasi tentang makna seni kepada orang lain, seperti tim perawatan sebuah instansi. Olivera (Malchiodi, 2003:251) Konselorharus teliti dalam menentukan batas-batas kemampuan mereka untuk menggunakan seni dalam konseling dan mengenali kapan konsultasi atau rujukan ke konselor seni ditunjukkan. Isu-isu lain yang terkait dengan penggunaan seni dalam terapi termasuk kerahasiaan, dokumentasi, kepemilikan, penelitian dan publikasi. Sebagai aturan praktis, karya seni harus diberikan semua pertimbangan dan perlindungan (Hammond \& Gantt, 1998). Konsekuensi termasuk menggunakan hati-hati ketika memasuki bahan catatan ke konseli, mengambil foto dari konseli karya seni hanya setelah persetujuan tertulis telah diberikan, dan cukup menyamarkan identitas dari konseli yang karyanya digunakan dalam penelitian dan publikasi. 


\section{KESIMPULAN}

Mahasiswa dalam pergaulan cenderung menutup diri dan menarik diri dari teman. Mahasiswa menutup diri dengan tampil bukan menjadi diri sendiri, dengan tidak memberikan informasi keseluruhan tentang dirinya. Mahasiswa cenderung hanya menampilkan informasi terluar dari dirinya. Self disclosure adalah proses memberikan informasi mengenai pikiran dan perasaan secara suka rela kepada orang lain, yang dimulai dari luasnya pengungkapan diri sampai dengan pengungkapan lebih mendalam.

Self disclosure yang lebih luas dan mendalam tidak bisa dilakukan oleh mahasiswa, akan mengakibatkan hubungan persahabatan yang kurang harmonis. Konseling yang terbaik mempekerjakan kualitas artistik yang memungkinkan individu untuk mengekspresikan sendiri dengan cara yang kreatif dan unik. Prosedur yang disajikan di sini mewakili beberapa dari cara seni rupa dapat digunakan secara efektif untuk membantu orang mencegah dan menyelesaikan masalah. Untuk mencegah masalah self disclosure pada mahasiswa salah satunya dapat dilaksanakan pelayanan konseling art dengan menggunakan gambar. Konseling art dengan gambar berfungsi baik sebagai katalis dansebagai penyaluran untuk memahami diri sendiri dalam konteks dunia yang lebih besar. Konseling art dengan gambar dilaksanakan melalui mengaduk perasaan dan membuka kemungkinan. Dengan demikian, melalui mempengaruhi kesadaran, penggunaan art dalam konseling menciptakan kemungkinan dan memperluas cakrawala sehingga dunia menjadi selalu baru.

\section{DAFTAR PUSTAKA}

Leung, L. 2002. Loneliness, Self-Disclosure, and ICQ ("I Seek You") Use.Cyberpsychology \& Behavior. School of Journalism \& Communication. Mary Ann Liebert, Inc. Volume 5, Number 3, pp 241- 251

Sprecher, S. \& Hendrick, S. 2004. Self-Disclosure In Intimate Relationships : Associations With Individual and Relationship Characteristics Over Time. Journal of Social and Clinical Psychology, Vol. 23, No. 6, pp. 857-877.

Ziv-Beiman, S. 2013. Therapist Self-Disclosure as an Integrative Intervention. Journal of Psychotherapy Integration. American Psychological Association. Vol. 23, No. 1, 59-74 1053-0479/13/\$12.00 DOI: $10.1037 / \mathrm{a} 0031783$

Matulaitiene, KZ \& Paluckaite, U. 2013. The Relation Between Teacher's SelfDisclosure and Student's Motivation To Learn. European Scientific Journal October 2013 edition vol.9, No.28 ISSN: 1857 7881 (Print) e - ISSN 1857- 7431.pp 456469.

Hargie, O. 2011. Skilled Interpersonal Communication Routledge. Research, Theory and Practice. Fifth edition: Landon and New York.

Hill, A. Watson, J. Rivers, D. \& Joyce, M. 2007. Key Themes in Interpersonal Communication: Culture, Identities and Performance. New York: Open University Press.

Chibbaro, JS. \& Camacho, H. 2011. Counseling: Using the Visual Expressive Arts as an Intervention. GSCA Journal. Pp 41 - 43

Nucho, AO. Jakab, I. \& Ahsen, A. 2003. Art Therapy. Charles c Thomas Publisher, LTD. Springfield Illinois U.S.A. 2003 